\title{
BMJ Open Qualitative study exploring patients experiences of being diagnosed and living with primary bone cancer in the UK
}

\author{
Ana Martins, ${ }^{\oplus 1}$ Jeremy S Whelan, ${ }^{\oplus 1}$ Lindsey Bennister, ${ }^{2}$ Lorna A Fern, ${ }^{1}$ \\ Craig Gerrand, ${ }^{3}$ Maria Onasanya, ${ }^{1}$ Lesley Storey, ${ }^{4}$ Mary Wells, ${ }^{\circ}{ }^{5}$ Rachael Windsor, ${ }^{1}$ \\ Julie Woodford, ${ }^{6}$ Rachel M Taylor ${ }^{1,7}$
}

To cite: Martins A, Whelan JS, Bennister L, et al. Qualitative study exploring patients experiences of being diagnosed and living with primary bone cancer in the UK. BMJ Open 2019;9:e028693. doi:10.1136/ bmjopen-2018-028693

- Prepublication history and additional material for this paper are available online. To view these files, please visit the journal online (http://dx.doi. org/10.1136/bmjopen-2018028693).

Received 02 January 2019 Revised 12 August 2019 Accepted 30 August 2019
Check for updates

(C) Author(s) (or their employer(s)) 2019. Re-use permitted under CC BY-NC. No commercial re-use. See rights and permissions. Published by BMJ.

For numbered affiliations see end of article.

Correspondence to

Dr Ana Martins;

ana.martins1@nhs.net

\section{ABSTRACT}

Objective The aim of this study is to explore the experiences of patients with primary bone cancer. Design Qualitative study design using semistructured interviews and focus groups.

Setting Hospitals across the UK and recruitment through UK sarcoma charities and support groups.

Methods Semistructured telephone/face-to-face interviews and focus groups with a purposive sample of 26 participants. Data were analysed using Framework Analysis.

Participants Patients $(\mathrm{n}=26)$ with primary bone cancer aged $13-77$ years. The majority were male $(69 \%)$, white $(85 \%)$; diagnosed within 4 years (54\%); and had lower limb sarcoma (65\%). Ten participants had undergone an upper/lower limb amputation (39\%).

Results The health-related quality-of-life domains of physical, emotional and social well-being and healthcare professionals' role were the overarching themes of analysis. The physical domain anchored patient experiences. The intensity and length of treatment, the severity of side-effects, the level of disability after surgery and the uncertainty of their prognosis had an impact on patient's self-image, confidence, mood and identity, and caused disruption to various aspects of the patients' social life, including their relationships (emotional and sexual) and participation in work/school and leisure activities. Adaptation was influenced by the way patients dealt with stress and adversity, with some finding a new outlook in life, and others struggling with finding their 'new normal'. Family and friends were the main source of support. Healthcare professional's expertise and support was critical. Rehabilitation services had a considerable role in patient's physical and emotional well-being, but inequitable access to these services was apparent.

Conclusions This study described the impact of primary bone cancer on patients' well-being and adjustment over time with the identification of influencing factors of better/worse experiences. It showed that impact was felt after end of treatment and affected patients at different life stages. Holistic models of survivorship care are needed.
Strengths and limitations of this study

- This study is an in-depth exploration of the experiences of 26 patients with primary bone cancer.

- The study population varied considerably by age at, and time from, diagnosis, gender and anatomical location.

- This study includes the experience of patients who had undergone amputation and other surgical interventions and treatment types.

- Self-selected participants might not be representative of the experiences of patients with bone sarcoma, but our findings are consistent with previous studies and add to the research by identifying the role of influencing factors of better/worse experiences.

\section{INTRODUCTION}

Primary bone cancer (PBC), also referred to as a bone sarcoma, is very rare and makes up approximately $0.2 \%$ of all cancers diagnosed in the UK. ${ }^{1}$ In 2015, 551 new patients were diagnosed with $\mathrm{PBC}$ in the $\mathrm{UK}^{2}$ The most common subtypes are osteosarcoma and Ewing sarcoma, which have a relatively high incidence in children and young people, and chondrosarcomas, more common in older age groups. ${ }^{3}$ There has been no major improvement in 5-year overall survival rates for patients with PBC over the past 25-30 years, with rates static at between $53 \%$ and $55 \%{ }^{4}$

To give the potential for cure, $\mathrm{PBC}$ requires complete surgical resection of the affected part of the bone. Thus, the patient characteristically experiences a lifelong limitation in physical activity. Less frequently, this can be achieved only by limb amputation, which leads to permanent disability. Given the high physical burden of the disease and its treatment and expectations of survival, poorer 
patient-reported outcomes ${ }^{56}$ are recorded in comparison to patients with other cancer types. ${ }^{7}$ For example, patients have reported poorer care experiences compared with other cancer types in the National Cancer Patient Experience Survey. ${ }^{8}$

When conducting a literature search, it became evident that there were inconsistent findings regarding the impact PBC may have on patients. ${ }^{5}$ While research has shown that patients may experience lower levels of physical functioning than population norms or control groups (eg, other cancer groups or healthy peers), there appears to be a lack of reliable information on the impact on patient's emotional and social well-being. ${ }^{5}$ Several studies comparing patients who undergo an amputation or limb sparing surgery have shown no differences in quality-of-life scores ${ }^{6-13}$; however, there are also reports of patients who had an amputation having poorer health-related quality of life scores compared with patients who had other types of surgery. ${ }^{14}$ The inconsistent results are also shown in studies that report that patients who had amputations had poorer mental health ${ }^{1516}$ but better feelings of self-worth ${ }^{16}$ compared with patients who had other type of surgery. Other studies have shown that those who undergo lower limb amputation tended to report more anxiety and depression. ${ }^{517}$

In addition to studies comparing patients who undergo an amputation and other types of surgery, there are studies comparing emotional and social well-being of patients with PBC with reference values either of general population data provided with the measure, non-cancer control data collected as part of the study or from patients with other cancer types. Overall, the findings reported are also inconsistent. ${ }^{5}$ Research with children and young people has shown improvement in emotional functioning over time $^{718}$; however, in studies with older patients, Paredes et $a l^{19}$ found no improvement in cognitive and emotional well-being from diagnosis to treatment and noted that they were worse than reference norms. No clear pattern can sufficiently explain these inconsistencies, although methodological differences including range of assessment tools used, outcome variables measured, as well as diagnosis, anatomical location, treatment and age groups have to be taken into consideration. ${ }^{5}$

Given the complexity and heterogeneity within the patient population, ${ }^{50}$ more research is needed to explore patients' experiences of PBC. The few qualitative studies that have been conducted have shown the adverse impact of having PBC on patient's emotional and social well-being; however, these studies focused on specific time points or specific aspects of the patient experience such as employment, ${ }^{21} 22$ and the long-term effects of PBC on current daily life, body image, future possibilities and identity. ${ }^{23-25}$

Both qualitative and quantitative studies shed light on the impact of PBC on patients' quality of life; however, more research is needed to understand in-depth, how patients of different ages, genders and treatment experiences live with and beyond PBC. ${ }^{5}$ Qualitative research provides richness, depth, nuance, context, multidimensionality and complexity of patients' lived experiences and is thus well suited to explore these patients' experiences. ${ }^{26}$ The aim of the current study was to explore the experiences of patients with PBC across the UK.

\section{METHODS \\ Design}

This was a qualitative study involving patients with $\mathrm{PBC}$, conducted as part of a larger qualitative study to develop a sarcoma patient-reported outcome measure-the Sarcoma Assessment Measure (SAM).

\section{Patient involvement}

The SAM is about patient experience of being diagnosed and living with sarcoma, thus patient involvement is a central part of the study. Initially, the SAM research team included the Chief Executive of Sarcoma UK (Lindsey Bennister), who represented the patient perspective in the design of the study. Maria Onasanya, who was diagnosed with sarcoma over 5 years ago, joined the study as a coinvestigator. Both Lindsey and Maria have assisted with data analysis and are coauthors in presentations and research papers. We are also working alongside Sarcoma UK and the Bone Cancer Research Trust to ensure patients are updated about the progress of the study (through study newsletters suitable for non-specialist audience) and they receive copies of all relevant outputs. Healthcare professionals working with patients with sarcoma have been engaged in data discussion, recruitment strategies and dissemination.

\section{Participants and setting}

The study was undertaken across the UK recruiting through specialist PBC clinical teams, sarcoma charities and patient support groups. Eligible patients were those with any diagnosis of bone sarcoma, aged over 13 (current age) and were able to communicate in English.

Patients were identified by recruiting hospitals who obtained and emailed the patient's written consent to the researcher; the researcher reaffirmed consent prior to conducting the interview. Patients less than 16 years gave their assent after consent had been received from their legal guardians.

Patients who contacted the research team after seeing information on social media from sarcoma charities were given information about the study and sent a consent form; the interviews proceeded following receipt of consent. Focus groups conducted in patient support groups were only conducted if all members consented to participate; information was given to members by the lead for the support group (either another patient or a clinical nurse specialist (CNS)) and the research team were invited to the group if patients had given their consent. 


\section{Data collection}

Data were collected through semistructured individual telephone interview (conducted by AM) and focus groups (led by AM and RT) conducted in sarcoma support group meetings (AM and RT are experienced researchers and were not involved in the patient's care). Young people less than 16 years took part in face-to-face interviews (parents were present during the interview). The interview schedule was developed from the literature ${ }^{27}$ and expert opinion (patients and healthcare professionals) and included questions about diagnosis, treatment timeline and experiences; physical and emotional health; and social well-being. This was not prescriptive and was purposefully flexible to enable the researcher to explore new and emerging experiences. ${ }^{28}$ This topic guide was shared with participants prior to the interview (online supplementary appendix 1), so they knew the topics covered (this allowed participants to decide whether they wanted to talk about the topics covered and gave them more control over the process). With permission, all interviews and focus groups were recorded and transcribed verbatim. Interviews lasted between 26 and $96 \mathrm{~min}$ and focus groups lasted 2 hours. Field notes were taken during and after the focus groups.

\section{Data analysis}

Data analysis was developed in two phases. Transcripts were broadly coded into the three functional domains of quality of life defined by Taylor et $a l^{29}$ 'subjective, multidimensional and dynamic (...) and includes aspects of physical, psychological and social function' (p1831). A preliminary framework was developed by AM including these three overarching domains which then evolved during analysis of the initial transcripts. Data were analysed line by line with the aid of QSR NVivo 11, a specialist software package used to assist with data storage, management and retrieval. The coded data were entered into a framework that included the overarching themes of quality of life and the themes that emerged from the data (the fourth overarching theme-healthcare professional's role emerge from the data). Within each overarching domain, data were coded into more detailed themes using in NVivo codes. For example, for the overarching theme of emotional well-being, a subtheme of coping mechanisms was identified. Data exploration of patients' experiences considering age, gender or if the patient had an amputation, helped uncover commonalities and differences. Initial coding was reviewed by the research team and revised following discussion.

\section{RESULTS}

Overall, a purposive sample of 34 of 121 patients participating in the wider SAM study were diagnosed with $\mathrm{PBC}$; 8 patients had craniofacial bone sarcomas and were not included in this analysis as they presented with experiences more akin to those with soft tissue head and neck sarcoma (data available from the overall study which includes patients with soft-tissue sarcoma). We report here the findings from the remaining 26 participants (table 1).

Four overarching themes structured the analysis: the health-related quality-of-life domains of physical, emotional and social well-being and the role of healthcare professionals. More detailed analysis revealed that the experience of sarcoma in relation to the quality-of-life domains was particularly influenced by the patient's stage in life (ie, if they were a teenager, young or older adult), the individual's coping strategies and social support, the nature and extent of adaptation that had to be made as a result of illness (referred to as the adaptive tasks of illness), and where they were in their disease trajectory (eg, diagnosis, treatment, end of treatment, follow-up or recurrence). These will be described throughout the presentation of results next.

\section{Physical well-being: it was literally the worst pain l'd ever experienced}

The physical domain anchored patient experiences and the impact of PBC on emotional and social well-being. The intensity of treatment (surgery, cycles of chemotherapy and/or radiotherapy), the severity of side-effects, the length of treatment or the level of disability after surgery were some of the key features of PBC influencing the experiences described by patients. Patients faced specific challenges at different points in their treatment pathway and these are presented in table 2 .

The extensive surgery required had a profound impact on mobility, with lessened strength, instability, loss of flexibility and poor balance. Patients described use of technical aids to their mobility such as crutches or a cane, use of a wheelchair or mobility scooter. Functional impairment caused major disruption in every aspect of the patients' life such as climbing stairs, lifting, driving and walking: "going up and down the stairs is a job of work, to be honest. It is quite tiring". Most patients described the frustration of not being able to be as active as before and this was felt long after end of treatment.

After lower limb amputation, as well as mobility being severely affected, patients needed to relearn activities of daily living, including going to the toilet, taking a shower and walking. A well-fitted prosthesis was crucial to successfully gain greater mobility. If this was achieved, it positively influenced their overall well-being; however, patients described having issues with their prosthesis which had a negative impact on their lives.

Given the impact on mobility and other everyday tasks, physiotherapy played a major role in the recovery process. It helped patients to become mobile and manage the long-term effects of surgery: "I found that when we stopped, I got lazy with walking which would then give me more problems with the back and the ribs and the side so I find that I have to go and see a physio every sixweeks".

Emotional well-being: I think emotional has been equally hard and challenging as the physical one

Overall, the experience of PBC was described as difficult and traumatic. Patients managed the stages of treatment 
Table 1 Participants' characteristics

\begin{tabular}{lrc}
\hline & $\mathbf{N}$ & $\%$ \\
\hline $\begin{array}{l}\text { Gender } \\
\text { Male }\end{array}$ & 18 & 69 \\
Female & 8 & 31 \\
\hline Age at study & & \\
M=40.5; SD=17.9, range 13-77 years & & \\
13-24 & 4 & 15 \\
$25-39$ & 11 & 42 \\
$40-65$ & 6 & 23 \\
$66+$ & 5 & 19 \\
\hline
\end{tabular}

Age at diagnosis

$\mathrm{M}=34.2 ; \mathrm{SD}=18.1$, range $8-77$ years

$\begin{array}{lrr}8-24 & 6 & 23 \\ 25-39 & 14 & 54 \\ 40-66+ & 6 & 23\end{array}$

\begin{tabular}{lrr} 
Marital status & & \\
\hline Married/civil partnership/cohabiting & 13 & 50 \\
\hline Single & 9 & 35 \\
\hline Other & 4 & 15 \\
\hline Employment & & \\
$\quad$ Employee full-time/part-time job & 10 & 38 \\
$\begin{array}{l}\text { Full-time education at school, college/ } \\
\text { university }\end{array}$ & 5 & 19 \\
$\quad$ Wholly retired from work & 5 & 19 \\
$\quad$ Other & 6 & 23 \\
\hline
\end{tabular}

Ethnicity

$\begin{array}{lrc}\text { White British/any other white background } & 22 & 85 \\ \text { Other } & 4 & 15 \\ \text { Time from diagnosis } & & \\ \text { 0-4 (years) } & 14 & 54 \\ \text { 5-20+ (years) } & 12 & 46\end{array}$

Treatment status

\begin{tabular}{|c|c|c|}
\hline On treatment & 5 & 19 \\
\hline Off treatment & 21 & 81 \\
\hline \multicolumn{3}{|l|}{ Where in the body was the sarcoma } \\
\hline Lower limb \pm other site & 19 & 73 \\
\hline Upper limb \pm other site & 5 & 19 \\
\hline Spine \pm other site & 2 & 8 \\
\hline \multicolumn{3}{|l|}{ Treatment type } \\
\hline Surgery alone & 8 & 31 \\
\hline Surgery and chemotherapy & 12 & 46 \\
\hline Surgery, radiotherapy and chemotherapy & 4 & 15 \\
\hline Surgery and radiotherapy & 1 & 4 \\
\hline Chemotherapy and radiotherapy & 1 & 4 \\
\hline \multicolumn{3}{|l|}{ Amputation } \\
\hline Yes & 10 & 39 \\
\hline No & 16 & 61 \\
\hline
\end{tabular}

and the physical and emotional consequences of PBC differently (ie, coping strategies) and some had to have professional support. While some patients described having low mood sometimes, others described having depression and made reference to suicidal ideation at some of their lowest points: "I still suffer from very bad depression now (...) emotionally, I wasn't expecting to be that demanding". Anxiety and fear of recurrence was the emotional aspect of having a PBC that was shared by all patients as being difficult: "you're left in a state of uncertainty, because obviously no-one can give you a definitive fiveyear outlook. You're constantly having re-scans and everything. You've been through a very big thing and it's not really over. It might be, but you don't know, so that level of uncertainty is tricky at first to sort of get to grips with". In table 3 the particular features of patients' experience at the stages of diagnosis, treatment decision-making, end of treatment (eg, end of treatment was a transition point when support was needed) and follow-up are presented, and table 4 has the coping strategies and how patients accessed professional support across the disease trajectory. Moreover, as mentioned previously, patients' emotional well-being was significantly affected by the way in which they experienced physical symptoms and disabilities. We will describe next how their experience of PBC affected their identity and body image.

The physical consequences of $\mathrm{PBC}$ were so pervasive they affected patients' identity, how they saw themselves and what they could expect from their body, a body with different abilities and restrictions: "I suppose just coming to terms with the fact that my body and my mind have changed and that's part of it. It's not just being ill and having the treatment, it's everything that comes afterwards too". Throughout participants' descriptions of their experiences, there was a continuous negotiation between the 'old' self and the changes imposed by their diagnosis and treatment, and the recovery process took time. There were also numerous examples of the way in which PBC treatment had affected patients' physical appearance, and as a result, their confidence and identity. While some changes were specific to the treatment phase, others were not, and the acceptance of the altered body was an ongoing challenge for patients "I didn't realise how much your body image affects your confidence. You know, that was something else that I would speak to the counsellor about that perhaps I couldn't speak about to my partner".

For patients who had an amputation, the pressure of trying to get back to 'normal', and to be seen as 'normal', was more salient than in patients who did not have an amputation. While some patients were able to resume or continue what they were able to do before the diagnosis others found the impact on their lives completely disruptive: "I had an amputation to deal with, so my identity from what I assumed I looked like had just been completely devastated really (...) I looked like something else, or someone else". There was a conscious knowledge that 'normal' was something different after the surgery and it had an impact on how they saw themselves and how others saw them. Being 
Table 2 Primary bone cancer impact on physical well-being at different points in the treatment pathway

\begin{tabular}{|c|c|}
\hline Time point & Impact on physical well-being \\
\hline At diagnosis & Onset of pain as the trigger to seek help for many patients \\
\hline \multicolumn{2}{|l|}{ During treatment } \\
\hline Chemotherapy & $\begin{array}{l}\text { The majority of patients gave vivid descriptions of how debilitating their treatment was and some } \\
\text { experienced frequent hospitalisations between chemotherapy cycles } \\
\text { Debilitating physical effects and frequent hospitalisations }\end{array}$ \\
\hline \multicolumn{2}{|l|}{ After treatment } \\
\hline Surgery & $\begin{array}{l}\text { Pain } \\
\text { Impact on mobility: lessened strength, instability, loss of flexibility and poor balance } \\
\text { For a few patients, falls were a concern and limited their activities as consequences could be severe: } \\
\text { "A little poodle, yapping like anything, I suddenly put all my weight, to jump out the way, onto my left leg } \\
\text { and I felt it break. It just literally split apart" }\end{array}$ \\
\hline Amputation & $\begin{array}{l}\text { Unfamiliar sensations of 'phantom pain' were particularly disconcerting } \\
\text { "There doesn't seem to be a lot of options in dealing with that, especially because, for me, I don't have } \\
\text { phantom pains every day, but l'll get it randomly (...) it can be quite disconcerting and painful" }\end{array}$ \\
\hline Long term effects & $\begin{array}{l}\text { Even many years after end of treatment, some patients were still struggling with the impact of treatment } \\
\text { "The memory thing, that's probably the one that affects me the most (...) it's probably got a little bit } \\
\text { worse (...) Whereas before cancer, everyone used to remark about how good my memory was" (young } \\
\text { adult, } 5 \text { years after treatment). } \\
\text { The longevity and unpredictability of some of these symptoms was troubling for patients }\end{array}$ \\
\hline
\end{tabular}

Table 3 Primary bone cancer (PBC) impact on emotional well-being at different points in the treatment pathway

Time point Impact on emotional well-being

At diagnosis Fear, shock, panic and feeling overwhelmed resulting in an inability to take in information It helped if they were given the opportunity to ask questions later or had someone with them at hospital appointments

During The physical impact was difficult to cope with and had an impact on emotional well-being:

treatment "I can remember asking at the clinic 'Does this get worse for each cycle because l'm already not coping?"'

Chemotherapy Chemotherapy was emotionally burdensome due to the physical impact it had on them

Amputation The devastating news of having to have an amputation and the lack of other options available were distressing "I couldn't really-, based on the journals that I was reading, and based on the information that was available at the time, amputation just seemed like such a life-altering decision"

End of The transition to being off treatment was challenging: the focus and structure of care while they were going through treatment treatment disappeared:

"It's difficult, sort of, coming to terms with everything (...) trying to get used to being on the other side of it and not having to deal with any of the chemo or anything"

Reflection during this transition period resulted in some patients not knowing how to cope with their thoughts and feelings such as the uncertainty associated with PBC:

"I think it was post-traumatic (...) every little thing that went wrong, I thought it had come back (...) so then I was constantly going to the doctors all the time (...) I wasn't sleeping very well"

Follow-up Fear of recurrence

The regular appointments and scans (part of follow-up care) were a source of anxiety, a constant reminder of the uncertainty and potential for recurrence

- The period before appointments was extremely stressful: "my anxiety levels peak, you know, just before my three monthly check-up, and then once l've had my check-up, I, kind of, come right back down (...) next three month, the cycle starts again (...) I would certainly say the first twelve months were awful"

Time from diagnosis influenced patient's emotional experiences

- Descriptions of feeling devastated, of losing their future, their identity were mainly present in the first two years from being diagnosed

Negative emotions

- Guilt at having survived

- Feeling upset due to the impact of the illness on their family 
Table 4 How patients managed the impact of primary bone cancer (PBC) on emotional well-being

\section{Coping mechanisms}

Strategies used by patients to manage the impact of PBC:

- Focus on positive aspects of life (with some patients stating how lucky they were to still be alive)

- Setting up goals which gave a sense of control over what was happening to them

- Problem-solving, focusing on getting all the information about their diagnosis and treatment

- Focusing on their own children while going through treatment and in their rehabilitation

- Focusing on getting better "I've got to deal with it, and I know I can get better"'

- Around half those interviewed acknowledged a positive change in their outlook in life "I just became more relaxed about life, and probably appreciated small things more than a lot of people"

How patients managed the decision to have an amputation:

- Focus on how it would increase their chances of survival: "I'm losing my leg, but l'm not losing my life"

- Focus on how it would remove the cancer from their body

- Talk with patients who had amputation and see that it was still possible to have a 'normal' life afterwards

- Talk to someone who had undergone limb sparing surgery: "having to live a life where you are constantly having to take pain-killers, is not really a good life. Although she would do it again, it's not something she would recommend for somebody who is young"

\section{Professional support}

Timing of access to support: no one specific time; some during treatment, for others many years from treatment ending Access to professional support varied on the type of professional seen and how patients got access to this support:

- Not discussing how they were feeling with their clinical team

- Feeling low mood, anxiety, mild depression for a period of time before sharing with professionals who signposted to support

- Seeing a psychologist while in hospital

- Referral by their general practitioner (GP): "I'm on the waiting list for a mindfulness course, which my GP has referred me on"

- Receiving counselling over the phone

- Home visits by professionals

- Psychological support provided in hospital/primary care not adequate so additional support sought from charities

- Youth support coordinators (only available for teenagers and young adults (TYA) treated in specialist TYA centres)

Barriers to support:

- Patients not wanting to look weak

- Patients finding it difficult to admit that after treatment they were not feeling happy

Facilitators of support:

- Being advised by other patients to seek help was often a catalyst

- Having a good relationship with the GP facilitated patient's disclosure of needing support dependent on others was hard, undressing in public spaces took time for them to get used to "Due to amputation, I don't want my wife to take me in the wheelchair somewhere here or there so, I have to wait until chemo is over and I might get a little bit better walking with my prosthetic and get a normal body". Others remarked on how the growth of paralympics had a positive impact on awareness of people with prostheses by the public.

In addition to the influence of type of surgery on the patient's experience, patient's stage of life also influenced the emotional experiences. In particular, young adults (ie, patients aged up to 40 years old) who were transitioning to a new job, building romantic relationships, wanting to start a family, described their identify, expectations for the future in terms of employment, romantic relationships being changed and away from their peers. For example, this young adult reflected on the emotional impact of infertility caused by treatment: "That made me feel really isolated from people (...) I've always wanted a family, so that has been probably the biggest thing that I've had to overcome".

\section{Social well-being}

Social well-being: Everyone was very supportive. Everyone came around

As described above, the physical and emotional impact of PBC and the effect of treatment on patients' body image had a profound impact on social activity and well-being. The diagnosis, duration of treatment, frequent hospitalisations and restrictions imposed during and after end of treatment caused disruption to various aspects of the patients' social life, including their relationships (emotional and sexual), work/school and leisure activities. The impact on these subdomains of social well-being and how these experiences varied according to patient's age or stage in life and disease-related factors are shown in more detail in online supplementary appendix 2. A common element of patients' experiences was feeling closer to their family, but the caring responsibilities the patient had varied according to whether they were teenagers, young or older adults (online supplementary appendix 2). Similarly it is shown how the impact on romantic and sexual relationships and fertility were mainly concerns of young adults (under 40 ), but the lack of discussion about sexuality and intimacy with their clinical teams was common irrespective of patient's age.

The impact of surgery and treatment on mobility and its side-effects affected patient's ability to participate in school/work, sports and social activities with peers and family (eg, patients described being excluded of playing with their children). The interlinked impact of physical and social well-being resulted in a negative effect on emotional well-being: "I was just really upset, because I want to go ice skating. I'm not allowed to go ice skating and it's just like, everybody else can do it, and I can't, and I'm just-, it's just, sort of, I was quite upset about it, because, I don't know, why did it happen to me?"

The analysis of the impact of PBC on different domains of social well-being also revealed that relationships had a central role in supporting patients in the management of the impact of PBC as described next.

Relationships: I've got very frustrated about things; she's dealt with that and supported me

Family and friends had an important role supporting patients through their treatment and recovery. The support received was both practical and emotional and had a particularly salient role for different age groups. For teenagers, parents had a central role in communicating 
with healthcare professionals and providing emotional and practical support. Many teenagers reported receiving messages of support though social media while they were in hospital, which made a positive difference. For adults, partners or family were mentioned as being important. Extended family support was crucial, with grandparents and sometimes friends helping parents (patient and partner) with childcare during the treatment phase: "You know, my partner still had to go to work, and so my mum looked after my children for me, and I'm quite fortunate".

Conversely, patients who had no partner or close family, or those with elderly parents who were not able to support them, had to rely on professional carers. When their mobility was compromised, this led to social isolation: "This severely restricts me. I only really leave the house to go to [family house] (...) I think I've only gone out at night, sort of, socially, since this happened [more than 2 years ago] probably about eight times"

Friends were important in making patients feel 'normal' again, by not treating them differently, by showing up and continuing to do leisure activities: "I was still on crutches (...)and just said, 'Thank you for this, it just made me feel normal" or even by using humour as described here: "My friends still act the same way around me. So far I have been called LongJohn Silver, Hopalong Cassidy, Hoppy, Ironside. Basically, they're all cracking jokes about it, and that I do like".

Most patients also described the benefits of being in contact with other patients, either face to face or online. This helped them to feel normal ("if you hear they're struggling about certain things and you can relate to them, you start realising it's normal'), share experiences and find out practical tips (eg, travel insurance) on how to deal with specific issues linked with their diagnosis and treatment.

\section{The role of healthcare professionals: They were experts in what they were doing}

The expertise of clinical teams was valued by participants, especially if their route to diagnosis had been long and complex, which was the case for most patients. The specialist skills and experience of clinical teams restored patients' trust in the healthcare profession, as this had often been eroded by the time patients got to diagnosis. Many patients described how the healthcare team worked collaboratively to best support them.

All participants referred to being given information by the specialist team, asking questions and feeling supported. However, the timing and delivery of information were not always optimal, with some patients receiving information over the phone and then having to wait for the appointment with the specialist team to have their questions answered or concerns clarified. This was a period of distress for patients, with some looking for information online, which led to more distress. In contrast, when patients were guided towards specific online resources after meeting with their specialist clinical team, they were very positive about this.

The CNS was a key point of contact for all patients, she/he provided practical and emotional support, information about diagnosis and treatment and support available (eg, support groups; professional psychological support). CNS was also described as being approachable and available: "So, [CNS] was really a stable point for me to go to for any sort of information or support".

The transition from specialist centres back to receiving care in local hospitals was at times problematic, as patients felt local care teams were not knowledgeable: "Awful. Nobody knew what to do with me (...)Nobody would use my Hickman line". Where physiotherapy needs were not met by local services, some patients had to access services privately instead "So, I suffer a dropped foot as a result (...)I was just given some exercises to do on a sheet (...) So, I've since been seeing a private physio. They've really helped and worked wonders for my leg". The importance of timely and expert physiotherapy support was consistently emphasised as crucial to recovery. For example, one patient said " $M y$ wheelchair was already here when I came home from hospital, but they immediately built a ramp, so I could get out of the house on my wheelchair (...) They were really good and I immediately started to feel so much better".

\section{DISCUSSION}

The aim of this study was to explore the experiences of patients with PBC. These cancers are characterised by: commonly being associated with severe pain as a presenting symptom, more often affecting younger people; the need for very intensive and toxic chemotherapy regimens; surgical treatments which cause lifelong morbidity; and unsatisfactory cure rates.

While the altered body and level of impairment had a significant impact on patient's physical, emotional and social well-being, it was shown that support and expertise of professionals involved in patients' care, the perceived emotional and practical support received/available and patients own way of adapting to the changes caused by PBC influenced the recovery process. In addition, patients' experience was influenced by where they were in their disease trajectory (eg, diagnosis, treatment, end of treatment, follow-up or recurrence) and their developmental stage in life (ie, if the patient was a teenager, a young or older adult). The disease trajectory helped explain that there were certain points in their pathway that were particularly challenging for patients (eg, end of treatment). Another important aspect was the stage where the patients were in their lives, if they were teenagers going through the challenges of school and establishing friendships or young adults establishing new romantic relationships, entering a new job or starting a family, or adults with children and mortgages, or older adults close to retirement or retired. These different challenges were intertwined with their experience of $\mathrm{PBC}$ and affected the support needed and how they managed their own experience.

Our study adds to the growing body of evidence supporting the need to adopt an age-specific approach to the management of patients with sarcoma as their 
support needs might be different. Research as shown, for example, that a cancer diagnosis during teenage and young adulthood has an acute and unique impact on this critical and complex stage of life development, disrupting physical health, social and educational goals as well as psychological well-being. ${ }^{30}$ This is further supported in a national survey of patients' experiences in the UK which showed differences according to ageteenagers and young adults were significantly more likely to report most side-effects and post-treatment concerns than older patients; elderly patients were more satisfied with the information and emotional support provided than younger patients. ${ }^{31}$

The main findings showed that physical impairment had a significant impact on a patient's identity, with patients trying to get back to 'normal' or finding a 'new normal', which meant changing or adapting their daily activities, leisure time and school/work; this extended long after the initial treatment phase. This is in line with findings from other qualitative research. ${ }^{142122} 2432$ In addition to the physical limitations following PBC treatment, self-perception and other's perceptions of the altered body interfered with patient's body image, which had an impact on confidence in social interactions (eg, not wanting to go out) and intimate relationships (eg, feeling less attractive), findings which are consistent with previous research. ${ }^{23} 3334$ This study showed that emotional well-being changed along the different phases of PBC trajectory with the first and second years after diagnosis particularly physically and emotionally challenging for patients. ${ }^{5}$ After the end of treatment, patients reported fear of recurrence and this was constantly brought to the forefront of their minds due to regular follow-up appointments and scans (mainly patients within 5 years of diagnosis). These findings are contrary to Fauske's et $a l^{23}$ findings where the majority of the eight patients with osteosarcoma in the lower extremity (who were aged 18-50 and had been diagnosed for 3-10years) who took part in the study did not report fear of recurrence. These contrasting results might be due to the focus of the interviews in Fauske's et $a l^{23}$ study-how has cancer changed your life and how it has changed you as a person-and our goal to cover patients experience from the point of diagnosis onwards.

Moreover, patients in our study reported low mood, depression, anxiety and even suicidal ideation, with a few patients reporting more severe cases of depression or anxiety. This is consistent with previous research that has shown that although the majority of participants reported non-clinical anxious and depressive symptoms a significant minority experienced clinically relevant distress symptoms long after their treatment ended. ${ }^{19}$ One last element in understanding patient's emotional well-being, shared by all, was the intensity and duration of chemotherapy and radiotherapy and how difficult it was for them physically and emotionally. Although exposure to intensive chemotherapy has been identified as adding to the risk for depression and somatic distress among both leukaemia and lymphoma survivors, ${ }^{35}$ we do not know the impact/risk of treatments on patients with PBC. Conversely, there were also reports of positive growth in our study. This was, for some, more straightforward due to their personality and/or timely professional and informal support available. But this might also reflect Bekkering's et $a l^{6}$ suggestion that similar psychological status of patients with sarcoma and healthy peers found in their study was due to positive emotions felt after completion of treatment and survival, in what was termed the 'response shift'.

It was in the absence of certain elements of support that more negative experiences were revealed. It was shown that family and friends gave emotional and practical support, but those who did not have this support were at risk for worse emotional and social well-being. While the majority of patients in this study reported adapting to the changes in mobility, there were some who had either their mobility severely compromised or were physically constrained by side-effects of treatment such as severe fatigue. These were also patients who were at higher risk for worse emotional and social well-being. Consistent with a review of survivorship after extremity sarcoma, ${ }^{5}$ this study showed that physiotherapy and psychological support were crucial to the recovery process; however, neither was reliably provided at the most needed times for all patients.

Our study had a number of limitations. A self-selected group of patients with a wide age range (13-77years old) and at different points in their timeline (from newly diagnosed to patients who were more than 10 years from diagnosis) took part in the study. While this heterogeneity of the sample might be representative of the heterogeneity of this group of patients, some patients were reporting their experience of being newly diagnosed while others were reflecting on their experience of more than 10years ago. It should be noted that patients described their experiences throughout the different phases and while newly diagnosed patients were able to give more detailed descriptions of that phase, this information was complemented by patients who had some perspective over their thoughts and feelings during that phase and what followed. Another limitation refers to the sample in terms of age, considering PBC peaks during adolescence/young adulthood, younger patients aged 13-24years (current age) accounted for $15 \%$ of participants in this study. While saturation was reached on the issues raised by those who participated, a larger sample would have given us greater certainty that we could identify all the key issues across all the age groups. Nevertheless, this is a qualitative study and the aim was not generalisability, but the in-depth and credible analysis of patients' experiences of PBC across different age groups, gender, time from diagnosis, treatment types and anatomical sites. Moreover, our study makes an important contribution to the evidence, most notably the influencing factors of patient experiences across time.

PBC has a negative impact on physical, emotional and social well-being. The extent of this impact might be felt 
long after treatment has ended or be specific to the end of treatment phase. Longitudinal studies are needed to better understand how patients recover, adapt and adjust to the changes imposed by diagnosis and treatment, their needs at different points in the timeline and the impact of the support received. In addition, prospective studies, whether qualitative or quantitative, must include an exploration of changes in sexuality, fears of recurrence and impact on social and work activities, in order to underpin more holistic models of survivorship care. In clinical practice, the assessment of support in different phases of the disease trajectory is important for the identification of patients who may be at a higher risk for poor adjustment, and therefore, for targeting screening measures and interventions to those patients most likely to benefit. Clinical interventions must take into consideration the timing and types of support provided. In particular for this population, it was shown again the need to ensure that patients have access to physiotherapy and psychology services and the relevance of support to return to work or school/university. Lastly, as improvements in survival seem elusive at the moment, improving the experiences and quality of life for this patient group is paramount. While qualitative research has detailed the disruption and changes in patient's experiences as a consequence of PBC, quantitative research has not consistently shown the impact of PBC on patient's quality of life; hence, research is needed to improve patient experience and quality of life measures.

Patients with PBC experiences were influenced by the intensity of treatment and side-effects that had an impact long after the treatment phase had ended. Mobility constraints, pain and fatigue influenced their participation in employment/education and leisure activities. The physical changes had also an impact on body image and their identity. Physical recovery was critical for their overall well-being and management of getting 'back to normal'. This study gave insight into factors which might influence adjustment over time, for better or for worse, showing that these affect patients at different life stages in which illness can disrupt important developmental milestones. These factors need to be taken into consideration to better understand and improve patients with PBC experiences.

\author{
Author affiliations \\ ${ }^{1}$ Cancer Division, University College London Hospitals NHS Foundation Trust, \\ London, UK \\ ${ }^{2}$ WMUK - Waldenstrom's Macroglobulinaemia UK, London, UK \\ ${ }^{3}$ Sarcoma Service, Royal National Orthopaedic Hospital Stanmore, Stanmore, UK \\ ${ }^{4}$ Department of Psychology, Birmingham City University, Birmingham, UK \\ ${ }^{5}$ Imperial College Healthcare NHS Trust, London, UK \\ ${ }^{6}$ Sarcoma Service, Royal National Orthopaedic Hospital Stanmore, Stanmore, UK \\ ${ }^{7}$ CNMAR, University College London Hospitals NHS Foundation Trust, London, UK
}

Acknowledgements The authors would like to thank all the Principal Investigators at the Trusts opened for recruitment - Fiona Cowie; Helen Hatcher; Amit Kumar; Dan Stark; Craig Gerrand; Robert Ashford; Claire McKenzie; Sarah Massey; Julie Woodford; Jonathan Gregory; Robin Young; Mariam Jafri; Paula Wilson;
Robert Ashford; Nicola Keay; and Paul Cool. The would also want to thank all the professionals involved in patient recruitment.

Contributors RMT, LAF, MW, LS, RW, JW, CG and JSW were involved in developing the protocol; AM coordinated the running of the study and was responsible for data acquisition; RMT, LAF, MW, LS, RW, JW, CG, JSW, LB and MO contributed to the analysis; AM, CG and MW drafted the manuscript. All authors critically revised and approved the final manuscript.

Funding This work was supported by Sarcoma UK (grant number SUK102.2016LG) and Bone Cancer Research Trust (grant number BCRT/49/16). RMT is funded by the National Institute for Health Research; LAF is funded by Teenage Cancer Trust. MW acknowledges support from the Imperial Biomedical Research Centre (BRC). JSW/ RMT acknowledge support from University College London Hospitals BRC.

Disclaimer The views are of the authors and do not necessarily reflect those of Sarcoma UK or Bone Cancer Research Trust, the NIHR/NHS or Teenage Cancer Trust. None of the funders were involved in conducting this review or drafting this manuscript.

Competing interests None declared.

Patient consent for publication Not required.

Ethics approval The Study was approved by the London Stanmore NHS Research Ethics Committee (reference: 16/L0/2152; IRAS reference: 217605).

Provenance and peer review Not commissioned; externally peer reviewed.

Data availability statement No data are available.

Open access This is an open access article distributed in accordance with the Creative Commons Attribution Non Commercial (CC BY-NC 4.0) license, which permits others to distribute, remix, adapt, build upon this work non-commercially, and license their derivative works on different terms, provided the original work is properly cited, appropriate credit is given, any changes made indicated, and the use is non-commercial. See: http://creativecommons.org/licenses/by-nc/4.0/.

\section{REFERENCES}

1. Gerrand C, Athanasou N, Brennan B, et al. Uk guidelines for the management of bone sarcomas. Clin Sarcoma Res 2016;6:1-21.

2. National Cancer Intelligence Network (NCIN). Bone and soft tissue sarcomas. UK incidence and survival 1996-2010 version 2.0. Available: http://www.ncin.org.uk/publications/reports/ [Accessed 25 Oct 2018].

3. Casali PG, Bielack S, Abecassis N, et al. Bone sarcomas: ESMOPaedCan-EURACAN clinical practice guidelines for diagnosis, treatment and follow-up. Ann Oncol 2018;29(Suppl 4):iv79-95.

4. Whelan JS, Jinks RC, McTiernan A, et al. Survival from high-grade localised extremity osteosarcoma: combined results and prognostic factors from three European osteosarcoma intergroup randomised controlled trials. Ann Oncol 2012;23:1607-16.

5. Kwong TNK, Furtado S, Gerrand C. What do we know about survivorship after treatment for extremity sarcoma? A systematic review. Eur J Surg Oncol 2014;40:1109-24.

6. Ginsberg JP, Rai SN, Carlson CA, et al. A comparative analysis of functional outcomes in adolescents and young adults with lowerextremity bone sarcoma. Pediatr Blood Cancer 2007;49:964-9.

7. Hinds PS, Billups CA, Cao X, et al. Health-Related quality of life in adolescents at the time of diagnosis with osteosarcoma or acute myeloid leukemia. Eur J Oncol Nurs 2009;13:156-63.

8. Department of Health. National cancer patient experience survey National report, 2017. Available: http://www.ncpes.co.uk/reports/ 2017-reports/national-reports-2/3579-cpes-2017-national-report/file; [Accessed 25 Oct 2018].

9. Eiser C, Darlington A-SE, Stride CB, et al. Quality of life implications as a consequence of surgery: limb salvage, primary and secondary amputation. Sarcoma 2001;5:189-95.

10. Hopyan S, Tan JW, Graham HK, et al. Function and upright time following limb salvage, amputation, and Rotationplasty for pediatric sarcoma of bone. J Pediatr Orthop 2006;26:405-8.

11. Akahane T, Shimizu T, Isobe Ken'ichi, et al. Evaluation of postoperative General quality of life for patients with osteosarcoma around the knee joint. Journal of Pediatric Orthopaedics $B$ 2007;16:269-72.

12. Expósito Tirado JA, Márquez Vega C, Muro Guerra C, et al. Calidad de vida $Y$ funcionalidad en pacientes pediátricos intervenidos de tumores óseos en miembros inferiores: Cirugía reconstructiva versus amputación. Rehabilitación 2011;45:313-9. 
13. Barrera M, Teall T, Barr R, et al. Health related quality of life in adolescent and young adult survivors of lower extremity bone tumors. Pediatr Blood Cancer 2012;58:265-73.

14. Davidge K, Bell R, Ferguson $\mathrm{P}$, et al. Patient expectations for surgical outcome in extremity soft tissue sarcoma. J Surg Oncol 2009;100:375-81.

15. Felder-Puig R, Formann AK, Mildner A, et al. Quality of life and psychosocial adjustment of young patients after treatment of bone cancer. Cancer 1998;83:69-75.

16. Barrera M, Teall T, Barr R, et al. Sexual function in adolescent and young adult survivors of lower extremity bone tumors. Pediatr Blood Cancer 2010;55:1370-6.

17. Singh R, Ripley D, Pentland B, et al. Depression and anxiety symptoms after lower limb amputation: the rise and fall. Clin Rehabil 2009;23:281-6.

18. Koopman HM, Koetsier JA, Taminiau AHM, et al. Health-Related quality of life and coping strategies of children after treatment of a malignant bone tumor: a 5-year follow-up study. Pediatr Blood Cancer 2005;45:694-9.

19. Paredes T, Pereira M, Simões MR, et al. A longitudinal study on emotional adjustment of sarcoma patients: the determinant role of demographic, clinical and coping variables. Eur J Cancer Care 2012;21:41-51

20. Tang MH, Castle DJ, Choong PFM. Identifying the prevalence, trajectory, and determinants of psychological distress in extremity sarcoma. Sarcoma 2015;2015:1-13.

21. Parsons JA, Eakin JM, Bell RS, et al. "So, are you back to work yet?" Re-conceptualizing 'work' and 'return to work' in the context of primary bone cancer. Soc Sci Med 2008;67:1826-36.

22. Brown A, Parsons JA, Martino C, et al. Work status after distal femoral Kotz reconstruction for malignant tumors of bone. Arch Phys Med Rehabil 2003;84:62-8.

23. Fauske L, Bondevik H, Bruland Øyvind S, et al. Negative and positive consequences of cancer treatment experienced by longterm osteosarcoma survivors: a qualitative study. Anticancer Res 2015;35:6081-90.

24. Fauske L, Bruland OS, Grov EK, et al. Cured of primary bone cancer, but at what cost: a qualitative study of functional impairment and lost opportunities. Sarcoma 2015;2015(supplement 1):1-10.
25. Fauske L, Lorem G, Grov EK, et al. Changes in the body image of bone sarcoma survivors following surgical treatment--A qualitative study. J Surg Oncol 2016;113:229-34.

26. Mason J. Qualitative researching. London: SAGE Publications Ltd, 2002: 1-10.

27. Storey L, Fern LA, Martins A, et al. A critical review of the impact of sarcoma on psychosocial wellbeing. Sarcoma 2019;2019:1-18.

28. Brédart A, Marrel A, Abetz-Webb L, et al. Interviewing to develop patient-reported outcome (pro) measures for clinical research: eliciting patients' experience. Health Qual Life Outcomes 2014;12:15.

29. Taylor RM, Gibson F, Franck LS. A concept analysis of healthrelated quality of life in young people with chronic illness. J Clin Nurs 2008;17:1823-33.

30. Morgan S, Davies S, Palmer S, et al. Sex, Drugs, and Rock ' $n$ ' Roll: Caring for Adolescents and Young Adults With Cancer. JCO 2010;28:4825-30.

31. Younger E, Husson O, Bennister L, et al. Age-Related sarcoma patient experience: results from a national survey in England. BMC Cancer 2018;18:991.

32. Earle EA, Eiser C, Grimer R. 'He Never Liked Sport Anyway' Mother's Views of Young People Coping With a Bone Tumour in the Lower Limb. Sarcoma 2005;9:7-13.

33. Lehmann V, Grönqvist H, Engvall G, et al. Negative and positive consequences of adolescent cancer 10 years after diagnosis: an interview-based longitudinal study in Sweden. Psychooncology 2014;23:1229-35.

34. Rasmussen DM, Hansen HP, Elverdam B. How cancer survivors experience their changed body encountering others. Eur J Oncol Nurs 2010;14:154-9.

35. Zebrack BJ, Zeltzer LK, Whitton J, et al. Psychological outcomes in long-term survivors of childhood leukemia, Hodgkin's disease, and non-Hodgkin's lymphoma: a report from the childhood cancer Survivor study. Pediatrics 2002;110:42-52.

36. Bekkering WP, van Egmond-van Dam JC, Bramer JAM, et al. Quality of life after bone sarcoma surgery around the knee: a long-term follow-up study. Eur J Cancer Care 2017;26:1-9. 